\title{
Scientific Paper on Sedimentation Challenges in Hydro-Power Storage Projects (Reservoir) and it's Mitigation Measures
}

Tejaswi Sharma

\begin{abstract}
This paper emphasizes on sedimentation challenges in reservoir thereby focusing on its mitigation measures to extenuate the challenges .The deterioration in the capacity brought about by the sedimentation has been clearly depicted and the mitigation measures to these challenges in order to enhance the existing capacity has been evinced. How the storage capacity of the reservoir gets depleted, the dams functioning becomes useless has been explored in this paper and some of the mitigating measures to it are properly defined. This paper tries to diagnose the challenges of sedimentation and its ill consequences brought about in storage projects with a broad view into some of its mitigating solutions.
\end{abstract}

Keywords: storage project, reservoir sedimentation, dam regulation, sediment estimation, sedimentation management, sustainability of reservoirs.

\section{INTRODUCTION}

It is widely admitted that the ecological condition of rivers are degraded mainly due to sedimentation. (Cordone \& Kelley, 1961; Hogg \& Norris, 1991; Hynes, 1970; Wood \& Armitage, 1997). Owing to loss of valuable storage, estimated at $35 \mathrm{~km}^{3}$ to $70 \mathrm{~km}^{3}$ per year, with an annual replacement cost of US\$10 billion to US\$20 billion, reservoir sedimentation is a thoughtful problem. (Palmieri et al., 2003). Reservoir sedimentation is one of the most important factors in the planning of a storage dam. So much so that the economic life of storage project is assessed from the estimated time it will take to be filled up with deposited sediments, because in many cases the life of the structures of the dam is longer than the period in which the reservoir is likely to be silted up (Qazi, 1997)

Generally sedimentation particularly affects the following elements: (H. Samadi Boroujeni)

$>$ the remaining live storage of the reservoir and its capacity in providing the degree of regulation which the project initially contemplated for;

$>$ structures already damaged by the passage of water and sediment (outlets) and which may have affect in the future (turbine components - runners and wicket gates).

For water resources sustainability, apt reservoir sedimentation management plays a pivotal role.

\section{OBJECTIVES}

The main objectives of the author in presenting this scientific paper is illustrated as below:

$>$ To know the real challenges of sedimentation in storage reservoir.

$>$ To emphasize on the loss of storage capacity of reservoir due to deposition of sediment.

$>$ To focus on the reservoir action due to excessive sedimentation.

$>$ To line up the techniques of estimation of sediments in the reservoir.

$>$ To enunciate the mitigation solutions for storage projects preservation.

\section{STORAGE PROJECTS}

Dams are generally used for retaining water as they are barrier for impounding water or underground streams. The purpose of constructing dams are opposite to what floodgates or leeves (dikes) are used for, in which the latter are used to manage or prevent water flow into specific land regions. For collecting or storing water too, dams are often constructed which can be evenly distributed between locations. (Wikipedia)

A reservoir (etymology: from French means a "storehouse"), artificial lake, storage pond or impoundment from a dam is used to store water, which is created in river valleys either by building up of dams or ground excavation or by conventional construction techniques (brickwork or cast concrete). (Encyclopedia)

The reasons for building dams are as follows: (U.S Corps of Engineers, 2007)

$>$ To provide water supply for towns, cities and mining sites; eg Warragamba Dam, Australia is the main water supply dam for the city of Sydney.

$>$ To contain and store waste (tailings) from mines; eg Omai Tailings Dam, Guyana, South America which stored waste from a gold mining operation.

$>$ To provide water supply for the irrigation of crops; eg Burrinjuck Dam, Australia which was built as the main head water storage for the Murrumbidgee Irrigation Area in New South Wales.

$>$ To generate electricity in hydro-electric power stations; eg Itaipu Dam, Brazil is the largest hydro-electric power station in the world. 
ISSN No:-2456-2165

To help control or mitigate floods; eg the Tennessee Valley Authority dams in the U.S.A. which help control floods on the Tennessee, the lower Ohio, and the lower Mississippi Rivers.

\section{SEDIMENTATION CHALLENGES IN STORAGE PROJECTS}

Hydro-power projects around the world are increasingly facing problems caused by river sediment transport. Many hydro-projects, especially in sediment-rich areas of the world, face severe operational problems, long before the end of the expected project life (Alam, 2001). Hence, sedimentation challenge is a devastating issue in case of storage projects.

\section{A. Constructon of Reservoirs and Thereby Degradation By Sedimentation:}

Before the existence of a reservoir, the river in which it is built endeavors to attain the condition of stability. Reservoir construction caused disturbance in the normal flow pattern however and sediment is deposited in the reservoir basin in an attempt to restore the original progress that has been made towards stability. During this process the river geometry is changed both upstream of the dam wall, due to deposition of sediment and, downstream, not by an excess of sediment, but by a lack thereof in the water. The "Sediment Hungry" water entrains sediment downstream of a dam wall, leading to degradation. The influence of these processes have negative implications for the environment, economic life and the design of reservoir. (George Annandale, 2000).

Large reservoirs invariably have tremendous influence in the environment, and engineers have in the past been accused, often justifiably, of being insensitive to these issues. However, the attitude of engineers have changed in the recent years and the intention is not to deal with environmental issues in great detail but merely to present a few examples of the influence disturbed sediment discharge in the rivers has on the environment and to highlight the importance of quantitative analyses.

Nearly about one per cent of global reservoir storage capacity i.e. around 50 cubic kilometers of sediment is trapped behind the world's dams every year.(Annandale, G.W)

B. Reservoir Sedimentation:

The process of deposition of sediment in the reservoir is called Reservoir Sedimentation or Reservoir Silting.

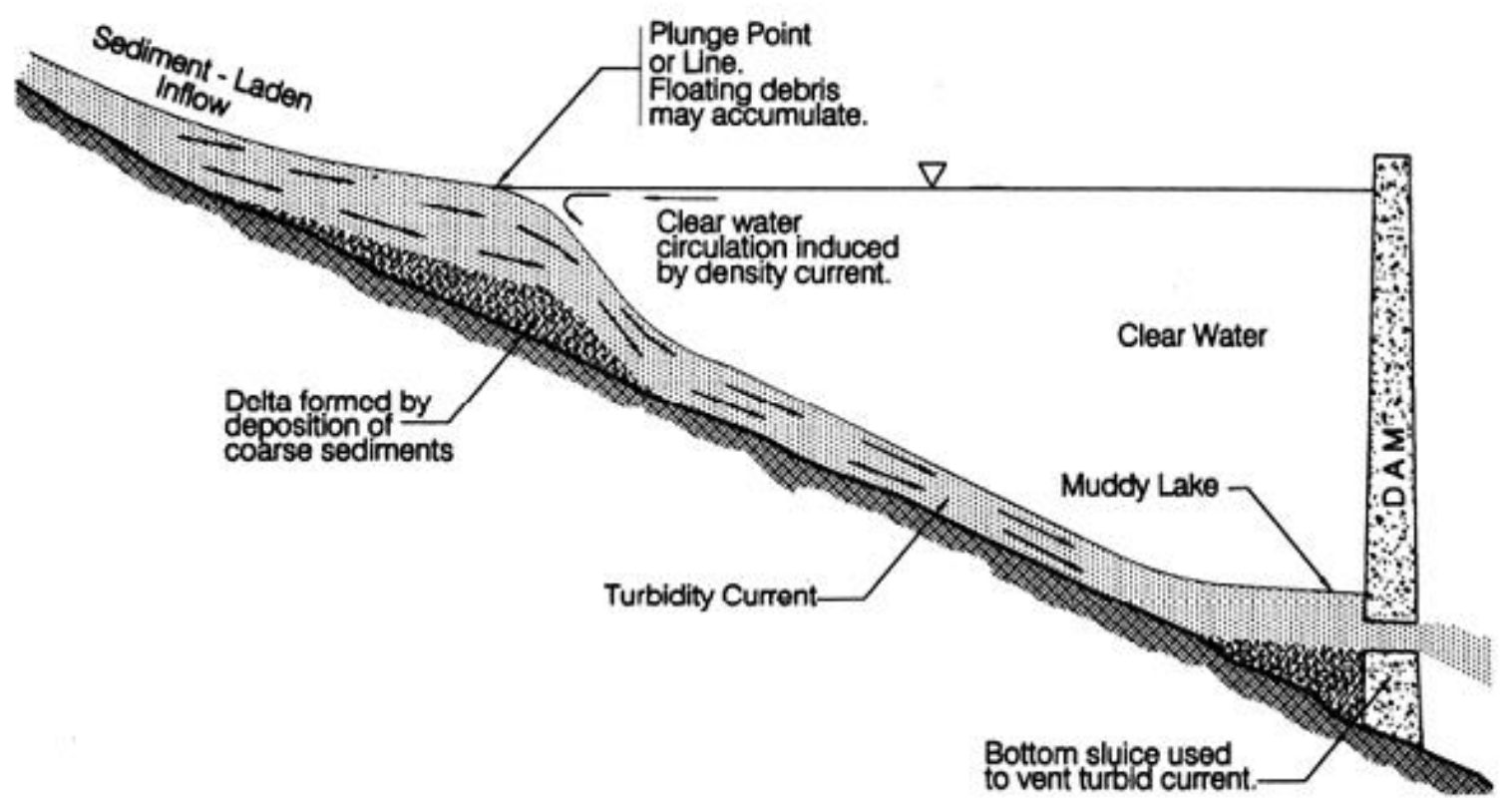

Fig 1:- Representation of the passage of a turbid density current through a reservoir and being vented through a low-level outlet.(Morris and Fan,1997)

Sedimentation is the major threat of loss of capacity of reservoir. Causes of reservoir sedimentation are many however; watershed, sediment and river characteristics are among the main natural contributing factors with the other being reservoir size, shape and reservoir operation strategy whereas manmade activities also play significant role particularly inland use pattern (Nazr, 2006). Sedimentation (difficult to predict) is a complex hydro-morphological process which was underestimated in the past and perceived as a minor problem thinking that it could be controlled by dead storage (certain volume of the reservoir at the bottom for accumulation of the sediment). However, every researchers and experts today believe that it is of paramount importance in design and implementation of sediment control measures as well as in the planning, operation and maintenance phases of the reservoirs (Siyam, 2005). Lead has been taken by countries like USA, China and Japan where reservoir sedimentation problems have been faced on many dams and attempts have been made to mitigate their effects. 
ISSN No:-2456-2165

\section{Effects of Sedimentation:}

The main adverse effects which can be faced due to the reservoir sedimentation can be listed under the following heads (S.S.Kirmani, 1999)

$>$ Depletion of Reservoir Capacity

$>$ Aggradation in the backwater area

$>$ Degradation in the downstream reach of the channel

$>$ Abrasion of structural components of the dam, waterways, metallic parts like gates, valves, liners etc and machinery parts if the project has hydro-power or pumping provisions.

$>$ Clogging of narrow water passages like tunnels and conduits and small openings, if the deposited material in the reservoir is liquefied due to heavy seismic shaking, and a flow slide takes place.

$>$ A devastating effect in the environmental, technical and economic impact.

Regarding fauna, fine sediments significantly alter macro invertebrate assemblages. Macro invertebrates have no backbone and are visible without magnification. Stream- bottom macro invertebrates include such animals as crayfish, mussels, aquatic snails, aquatic worms, and the larvae of aquatic insects. identified four ways in which fine sediment can affect macro invertebrates can be identified as: (Wood and Armitage (1997)

$>$ by altering substrate composition and changing the suitability of the substrate for some taxa (Hynes, 1970; Waters, 1995);

$>$ by increasing drift as a result of sediment deposition or substrate instability (Culpet al., 1986; Rosenberg \& Wiens, 1978);

$>$ by deposition on respiration structures affecting oxygen uptake or low oxygen concentrations associated with fine sediment deposits (Waters, 1995); and

$>$ by affecting feeding activities by reducing the food value of periphyton (Graham, 1990)and reducing the density of prey items (Peckarsky, 1984).

The mitigating measures can be traced out in an ongoing ecological and physically-based monitoring program for effective output as delineated below:

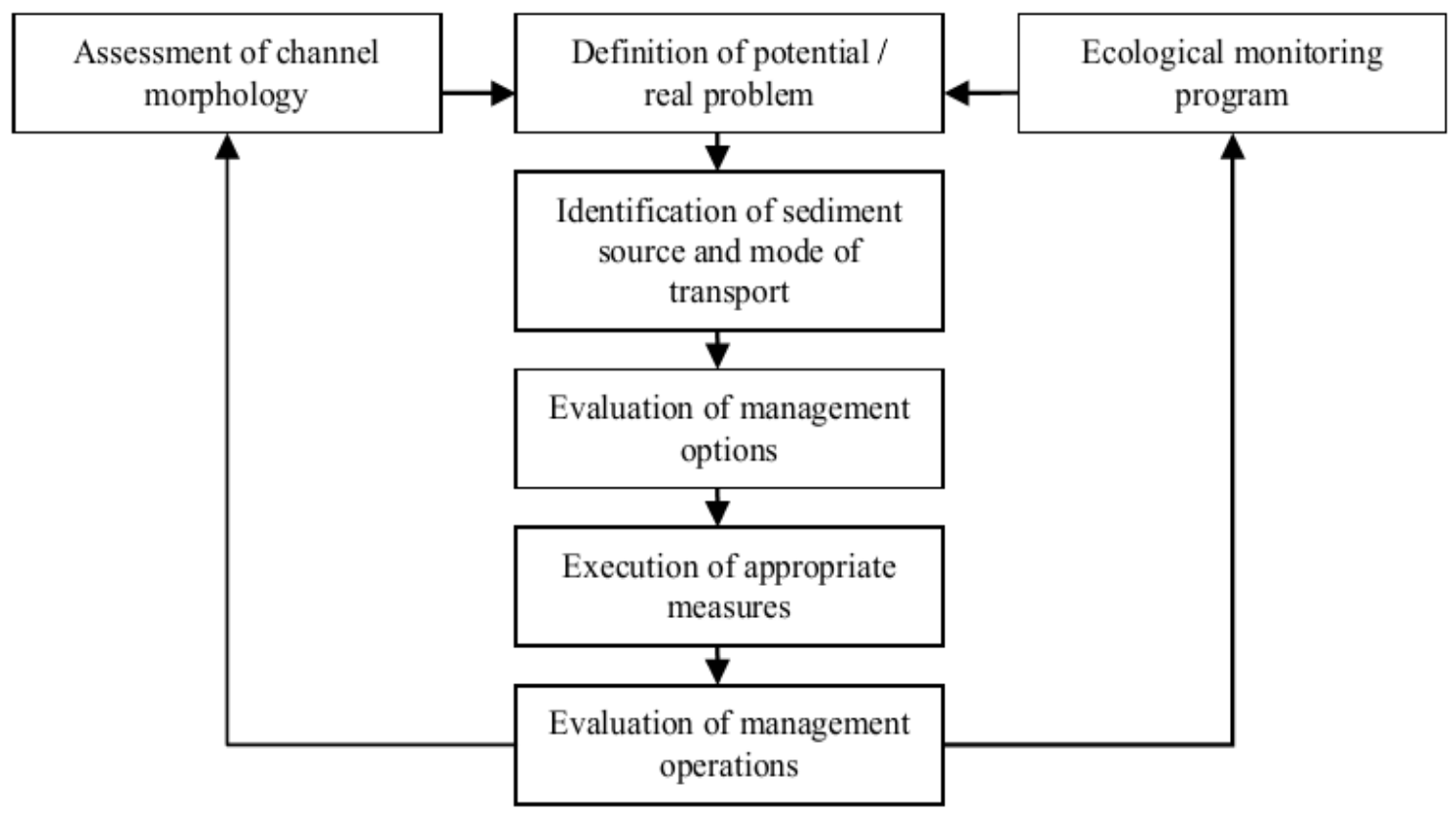

Fig 2:- A schematic management framework portraying the evaluation of effects of sediment accumulation in rivers (Wood \& Armitage, 1997).

\section{SEDIMENTATION YIELD AND SEDIMENTATION INDEX}

Average sediment load passing through a particular section per year is called sediment yield (tones $/ \mathrm{km}^{2} /$ year).Sediment yield can be calculated by any one of the following means:

$>$ Suspended Sediment Sampling

$>$ Lake or Reservoir Survey

$>$ Mathematical Modelling
USLE

$>$ MUSLE

$>$ RUSLE

The study has been widely used which co-relates the range of sediment concentration with three major variables (Longbien and Shumm,1965)

$>$ Average Precipitation

$>$ Temperature

Soil cover conditions 


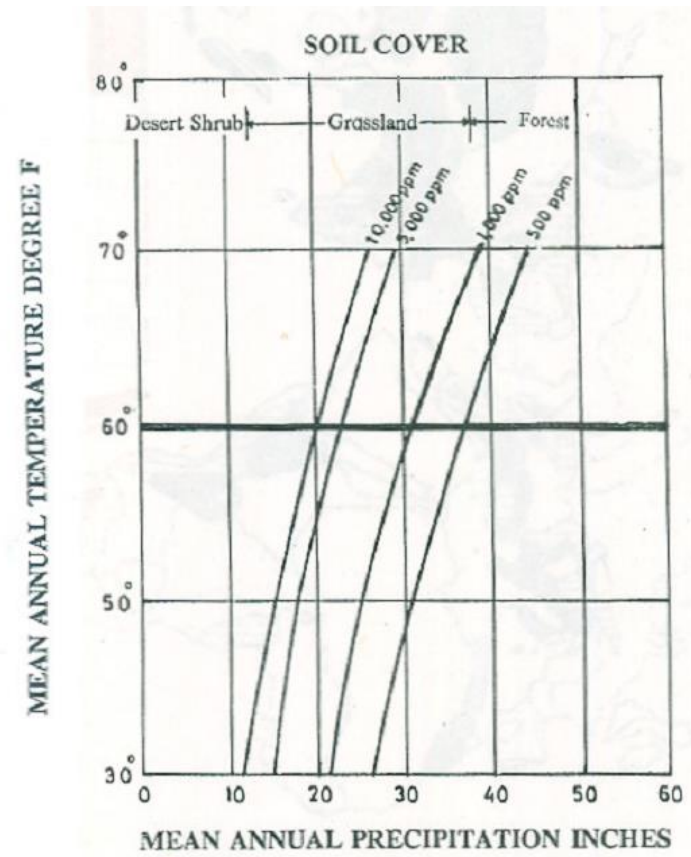

Fig 3:- Graph showing variation of Sediment Yield with different factors (Schumm,1965)

The estimation of total sediment quantity which is likely to flow into th reservoir annually is the most important factor which determines the degree of importance problem will have on the overall project planning and design of the reservoir structures.

If $\quad \mathrm{V} \quad$ is the volume of the reservoir and

$\mathrm{S} \quad$ is the average annual sediment yield (volumetric)

Then V/S is the 'Sedimentation Index', placing the project in the following intensity range classification-

\begin{tabular}{|c|c|}
\hline \multicolumn{2}{|c|}{ Intensity Range of Sediment Yield at Reservoirs (Haque, 1999) } \\
\hline Sedimentation Index (V/S) & Intensity Range \\
\hline$<50$ & Very High \\
\hline $50-150$ & High \\
\hline $150-300$ & Moderate \\
\hline$>300$ & Low \\
\hline
\end{tabular}

Table 1

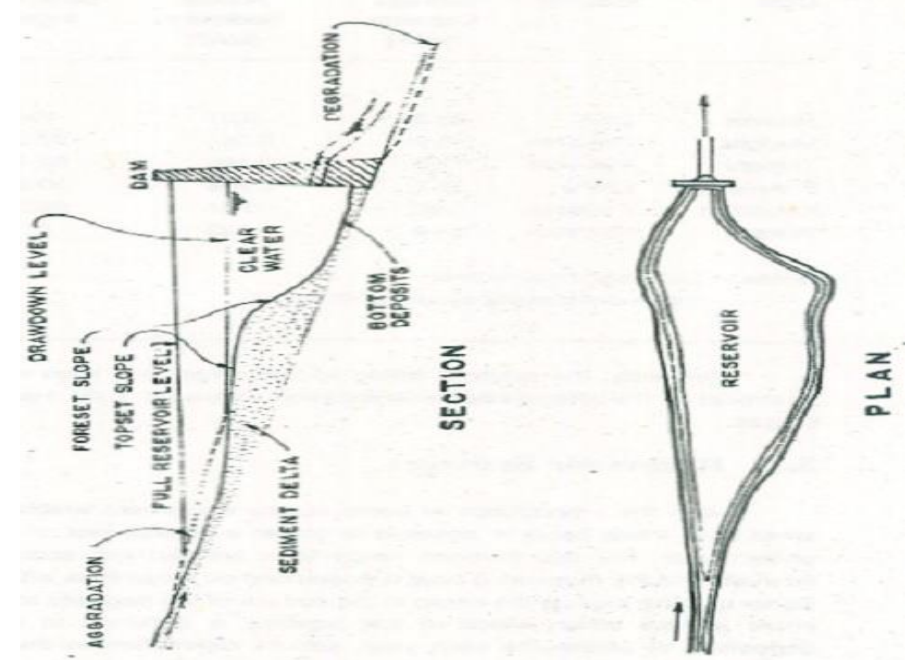

Fig 4:- Profile of Sediment Deposits in a Storage Reservoir (Haque,1999) 


\section{MITIGATING MEASURES}

Mitigating Measures applied for reservoir sedimentation can be pragmatically used for extenuating the challenges arised due to sedimentation.

A. Sediment Management Approaches:

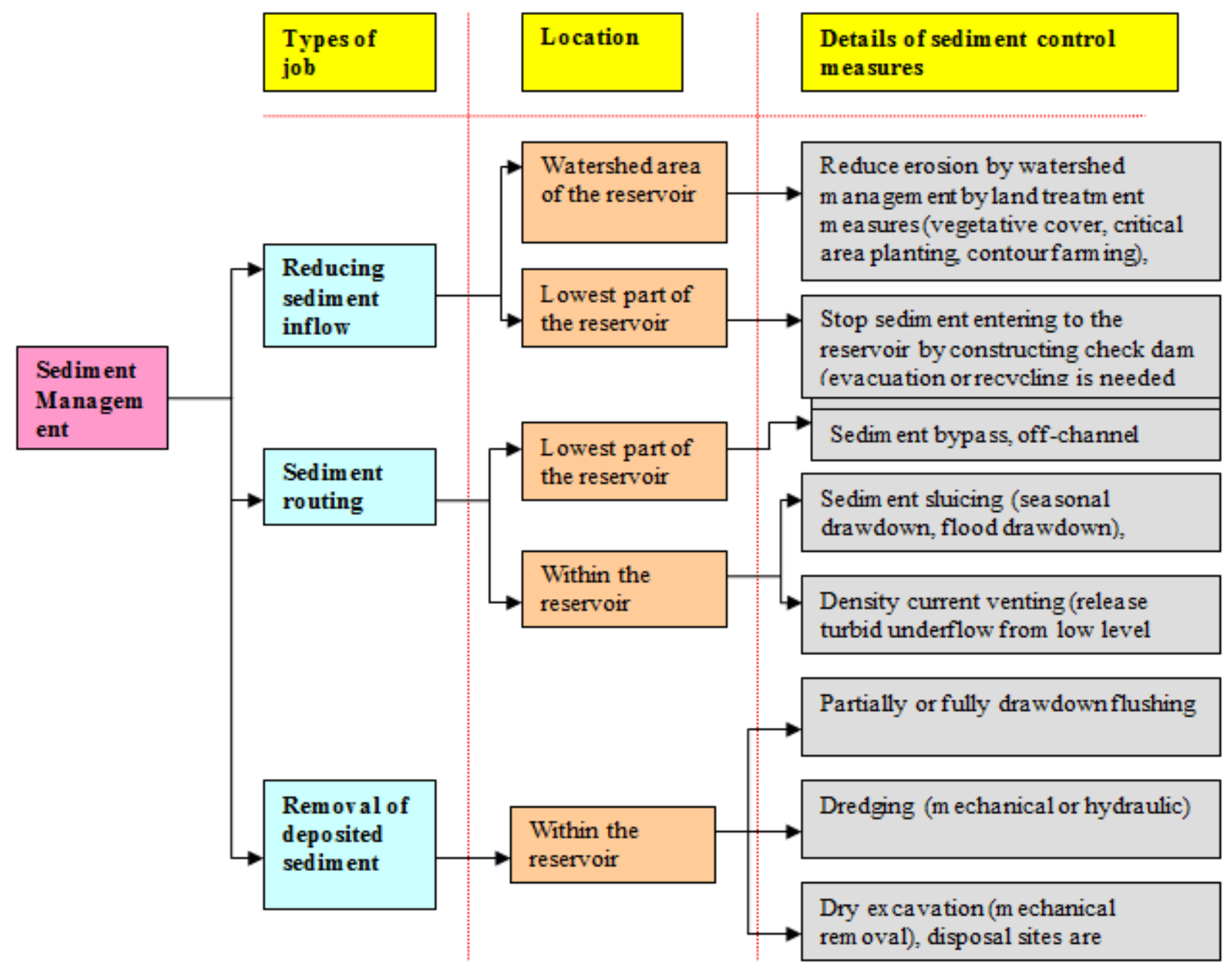

Fig 5:- Sediment management approaches (Sumi,2003 and Boillat et.al.,2003)

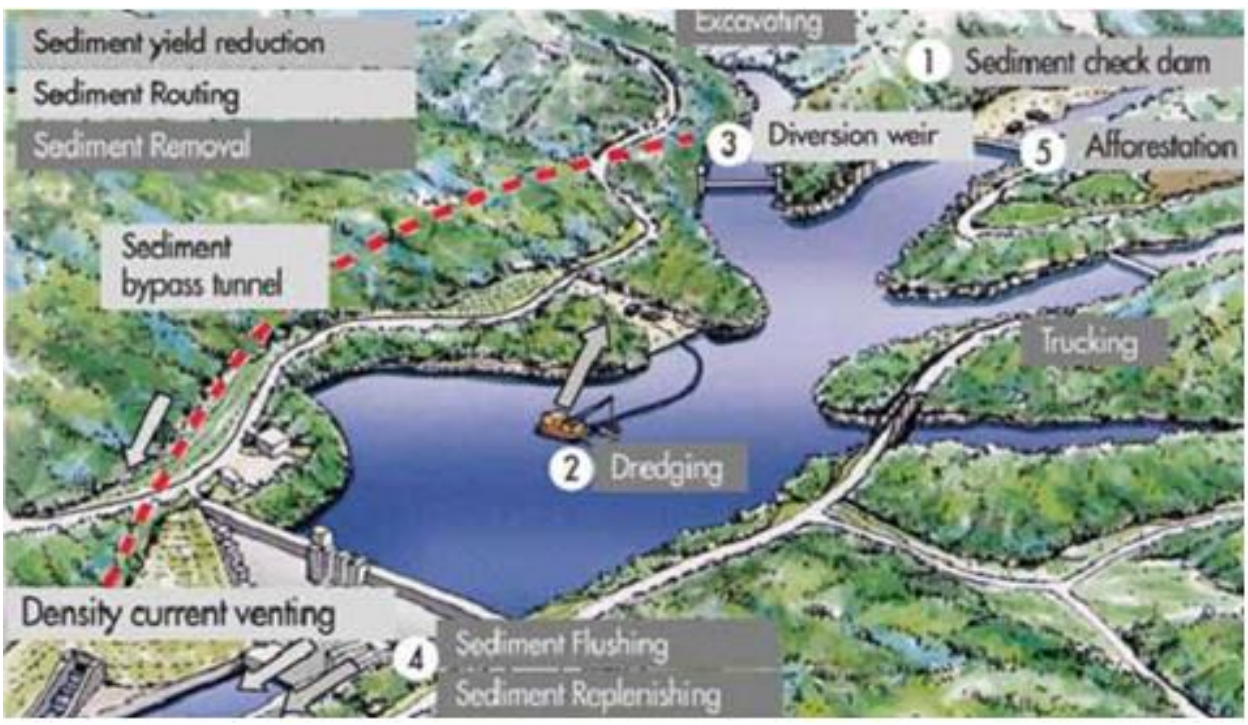

Fig 6:- Sediment management Strategies in Reservoirs (Sumi,2011) 
In terms of physical and technical conditions with socio-economic and environmental aspects, the sediment management for reservoir are often practiced. The general measures can be as follows (www.intechopen.com)

\section{Catchment Area Treatment (CAT Program) or Watershed Rehabilitation (Structural and non- Structural Measures)}

\section{- Reducing soil erosion:}

Soil and water conservation program is most effective way for reducing the sediment yield from the watershed but is not very popular due to long drawn and expensive nature. Implementing an effective conservation program in smaller catchments is more viable.(Roedjito and Harianto,1995).

- Reducing debris flow:

For mitigation purpose construction of debris basin (debris dam), which is a reservoir designed especially to trap sediment and debris is recommended (Vanoni, 1997; Mizuyama and Fujita,1996).

\section{- Check dam:}

The check dam can be effectively used as sediment trapping structure unless the supply of coarser sediments from the catchment is reduced by other conservation measures (HR Wallingford, 2004).

\section{Sediment Flushing :}

DHI (Institute for Water and Environment) has collaborated with the South African Universities of Pretoria and Stellenbosch, adapting of the sediment transport modules in MIKE 11 and MIKE 21C to reservoirs. The models have been verified on data from the Welbedacht Reservoir in South Africa. In this technique, the flow velocities in a reservoir are increased to such extent that deposited sediments are re-mobilized and transported through low level outlets in the dam.

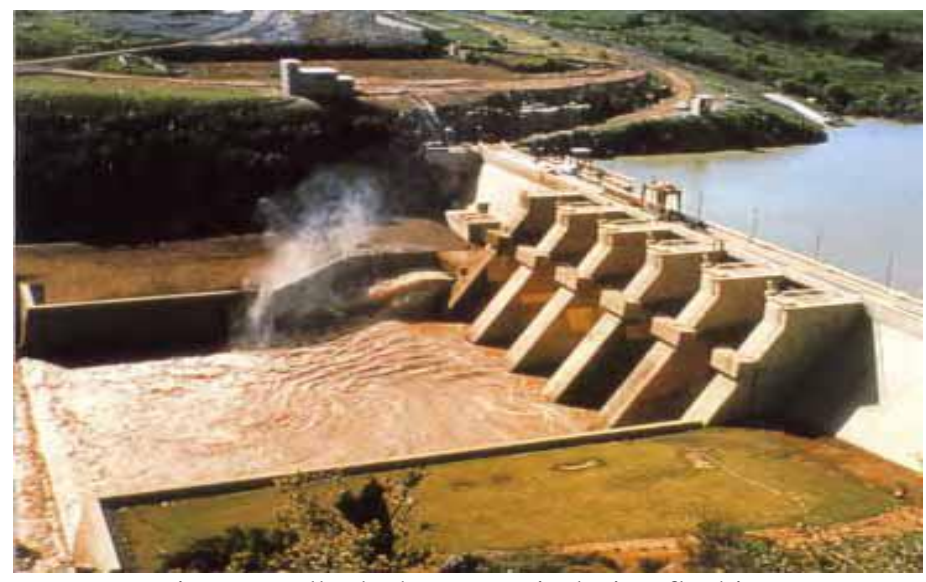

Fig 7:- Welbedacht reservoir during flushing

\section{Sediment Routing :}

It is a technique of routing the sediment inflow so as not allowing them to deposit within the reservoir. The methods adopted under this are:

- Sediment by pass:

The main purpose is to divert the sediment laden flood flows round a reservoir.

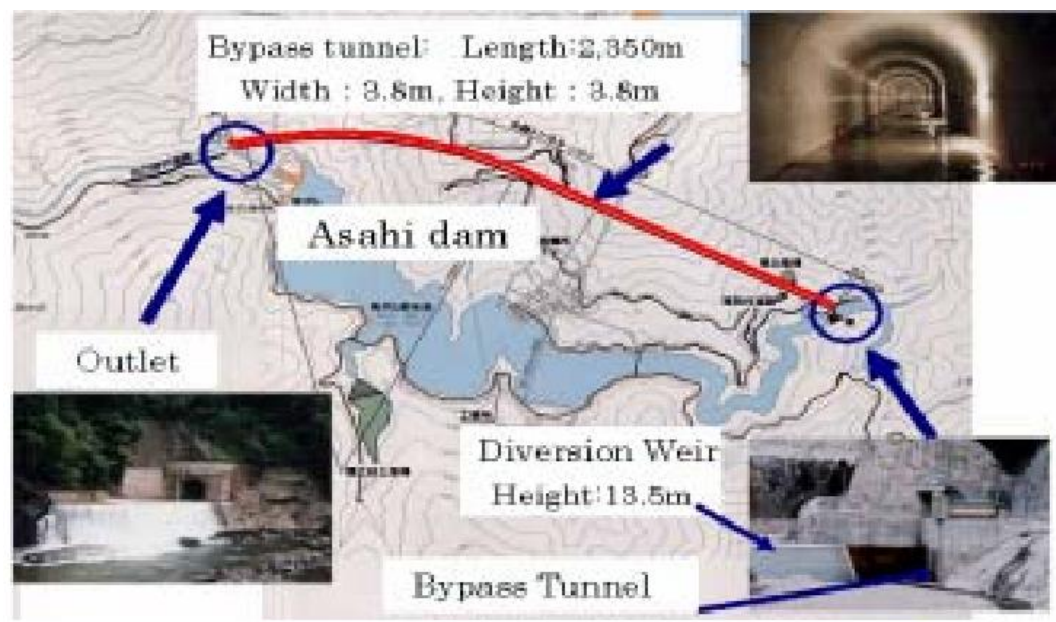

Fig 8:- Sediment Bypass Scheme at Asahi Dam 
ISSN No:-2456-2165

- Off-channel storage:

They are built adjacent to main river channel for diverting water from main river to the reservoir during times of low sediment concentration.

\section{- Sediment Sluicing:}

Sluicing is an operational technique in which incoming sediments are released from the reservoir by minimizing retention time. Sluicing operation is generally carried out at low reservoir level during the flood season and is specially recommended at the first flood when river water carries high sediment concentration. Various types of hydraulic sluicing method that have been experimented in

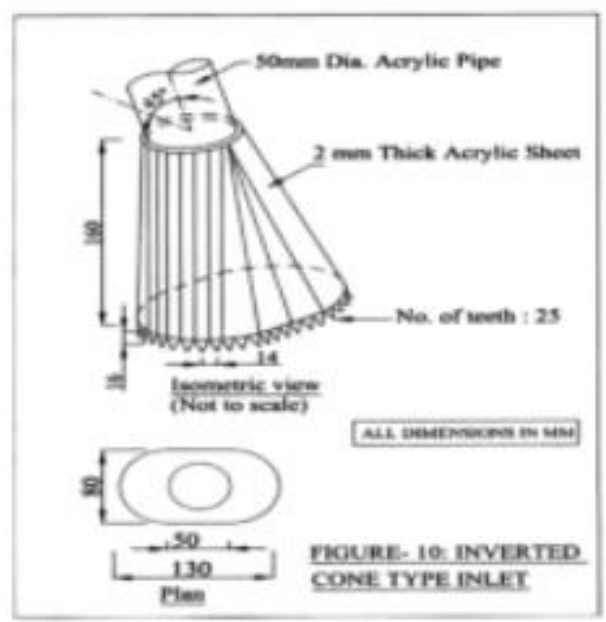

Fig 9:- Inverted Cone Sluicing Inlet and Saxophone Sluicing Inlet.

\section{- Density Current Venting:}

Measures for controlling heavy density currents are effectively tested using mathematical models with a vertical resolution. Examples of such models are the 3-D MIKE 3 models based on rectilinear or unstructured grids and with sediment transport modules describing the transport, erosion, settling and deposition of mud. MIKE 3 for deep and narrow reservoirs, the MIKE 11 Reservoir model with a vertical resolution is appropriate for simulating high density turbidity currents. (Basson and Rooseboom, 1997; Morris and Fan,1997; ICOLD,2004)
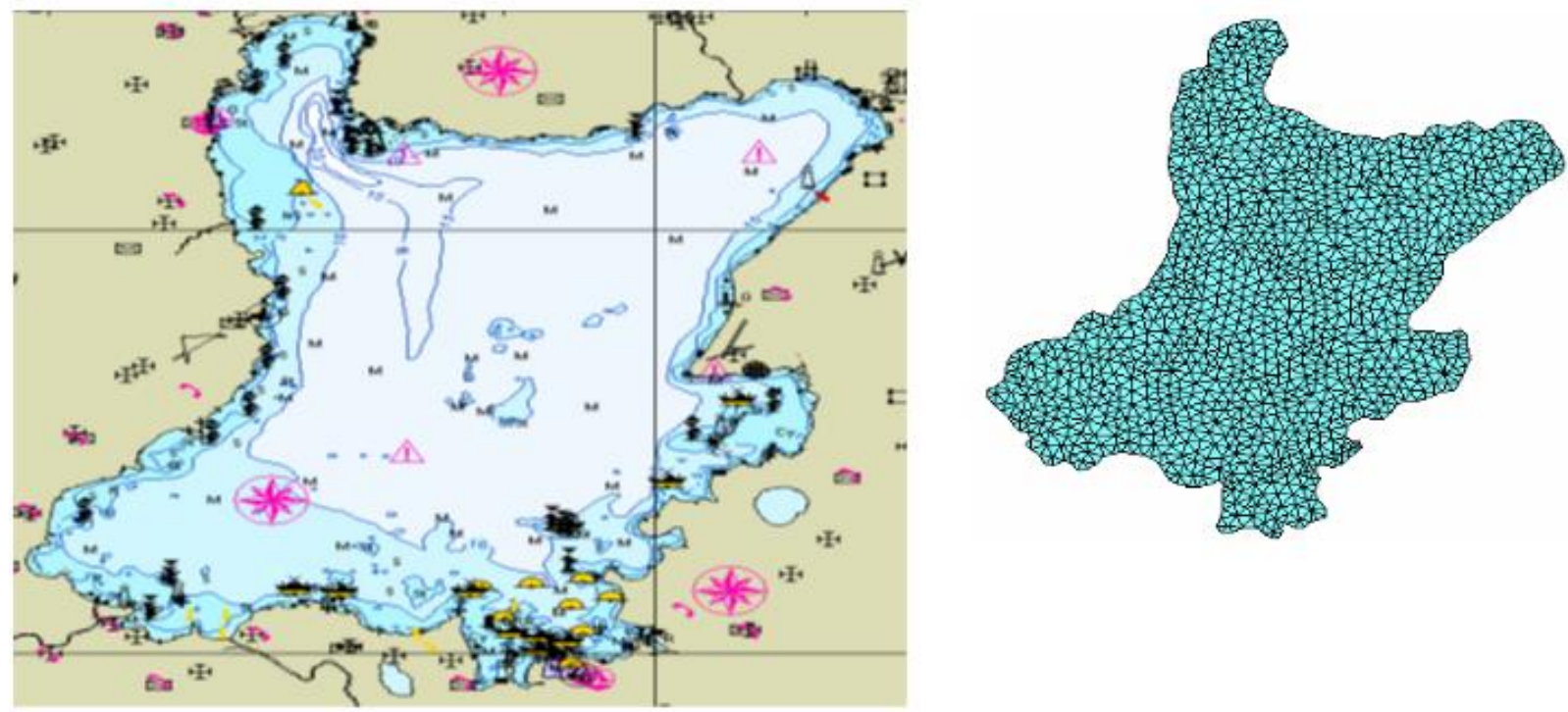

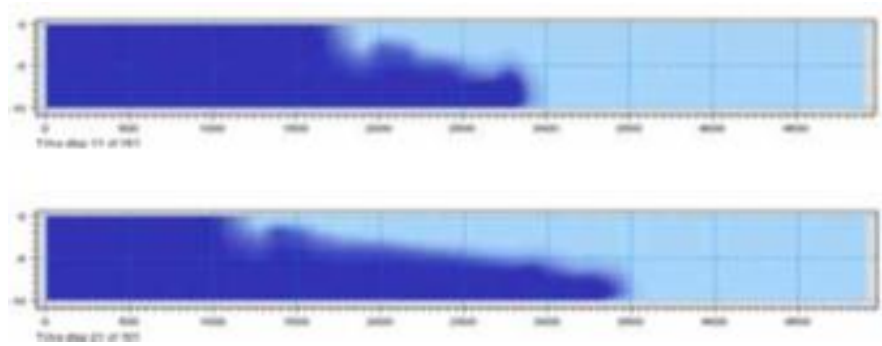

Fig 10:- MIKE 3FM for turbidity current modeling

Sediment removal and disposal:

It is the process of removal of sediment below the underlying water. The dredging process can be illustrated as below:

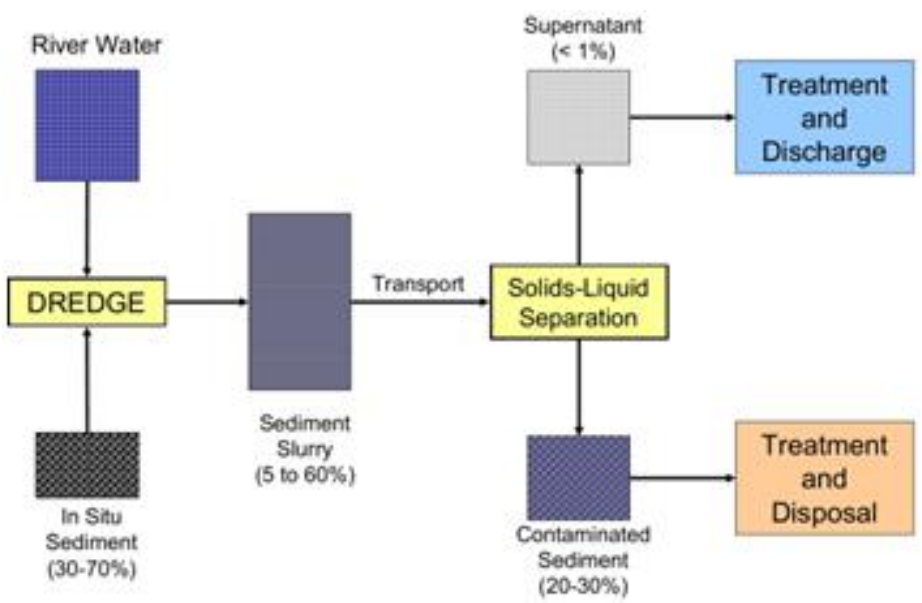

Fig 11:- Dredging Process (Hayes,2004)

\section{> Mechanical Dredging System:}

Mechanical dredges use different types of buckets to dig and lift sediment mechanically to the surface with minimal water entrainment. Transportation is usually via barge. (Basson, 1999)

\section{> Hydraulic Dredging System:}

Hydraulic dredges pump sediments from the bottom of the river in enclosed pipelines. It excavates the material and disposes of it either by pumping through a pipeline to the disposal area or by storing it is hopers which can be subsequently emptied over the disposal area (Basson,1999).

\section{Hybrid Dredging System:}

It uses combined mechanical lifting of sediments with hydraulic transport.
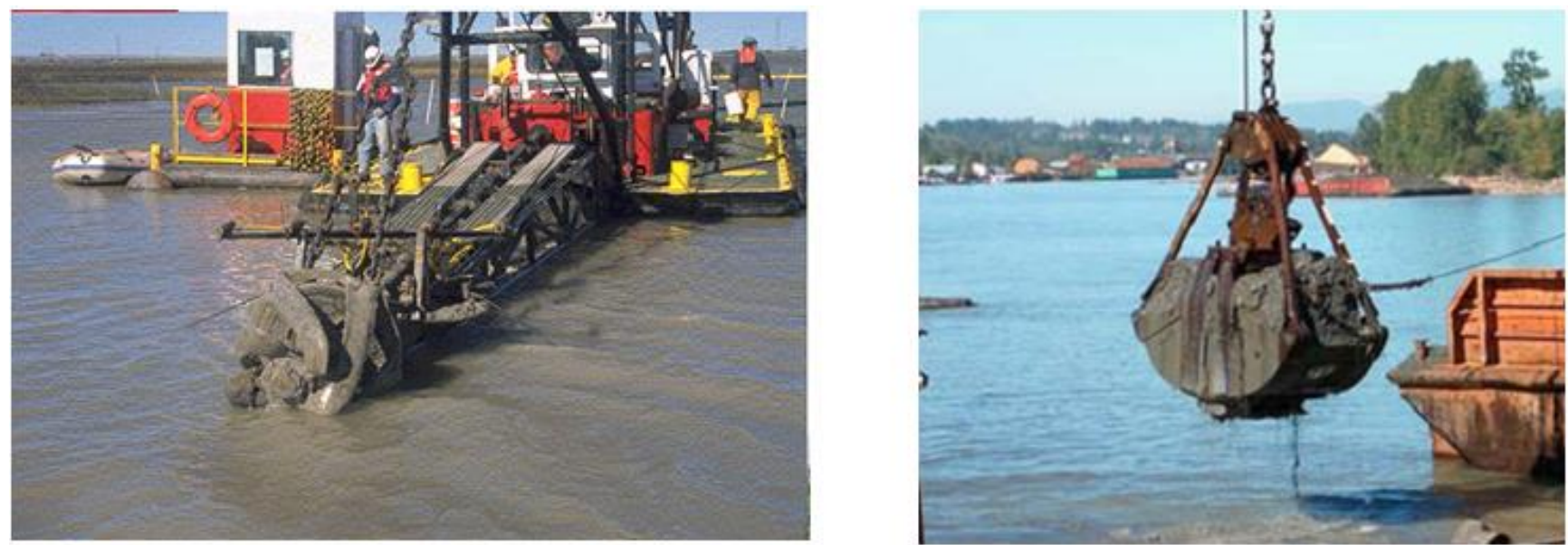

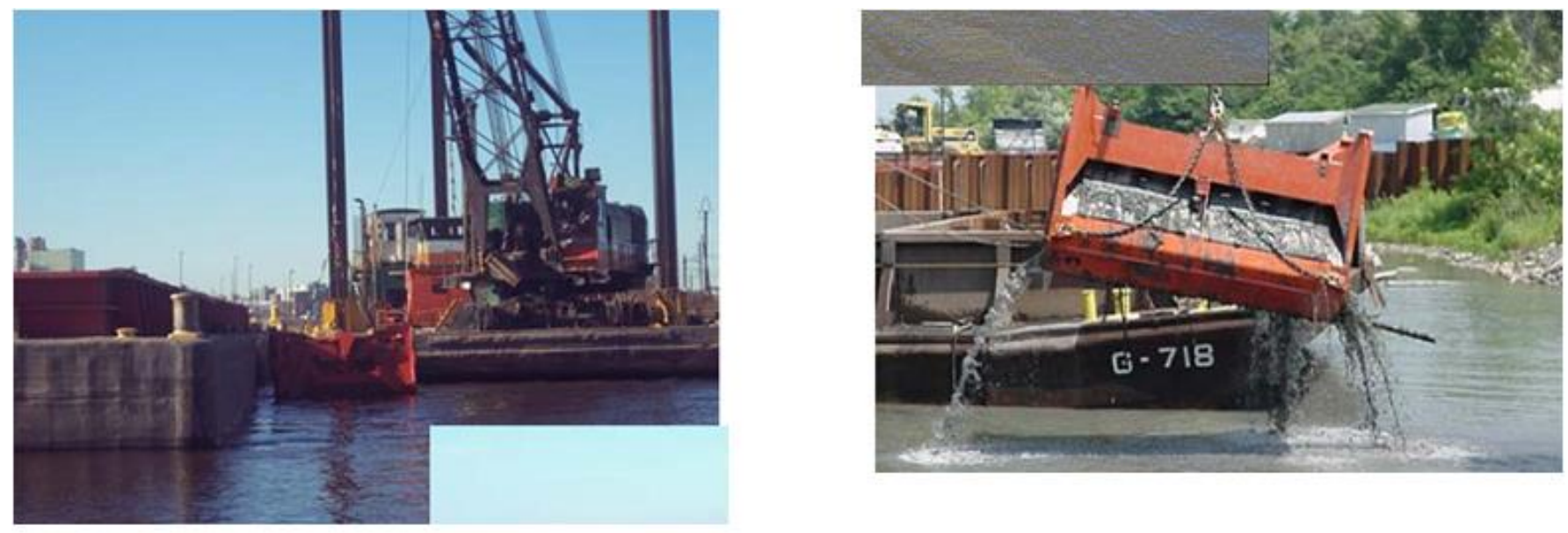

Fig 12:- Different Dredging Equipment (US Army Corps of Engineers, 2004)

\section{B. Sustainability of Reservoirs:}

Examining the durability of sustainability management and assessing the rectification required to existing dams and deteriorating resources is an important aspect, for which RESCON (Reservoir Conservation) and Computer Program (Palmieri et.al. 2003) can be applied to.

RESCON APPROACH comprises of three principal elements, which include determination of:

\section{Technical Feasibility of Reservoir Sedimentation Management: \\ It categorizes management approaches according to} location i.e. upstream of the reservoir and downstream (Palmieri et al, 2003; Morris and Fan,1997)

\section{$>$ Economic Feasibility of Reservoir Sedimentation Management:}

Benefit-Cost approach is used for economic feasibility that uses the Net Present Value (NPV) of the benefits and costs over the "design life" of the project. The Benefit-Cost Ratio $(B / C)$ is calculated with it.

\section{Environmental and Social Safeguards:}

At pre-feasibility stage, a complete Environmental Impact Assessment (EIA) is not justified to be conducted. In order to determine the relative magnitude of environmental and social impacts, a rating system is developed to estimate the compound effects (Palmieri et.al,2003).

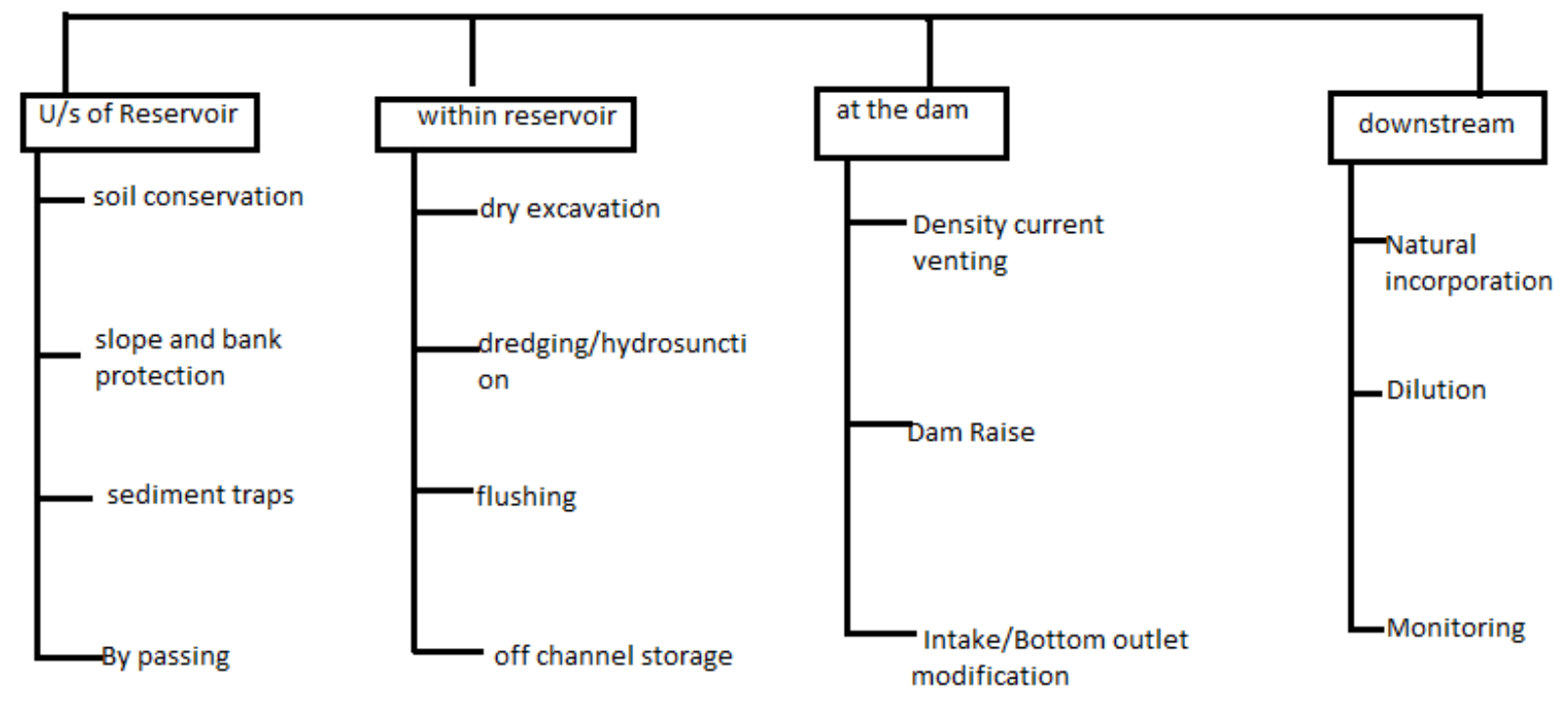

Fig 13:- Sediment Management approaches for sustainability of reservoirs (Annandale,2004) 


\section{CONCLUSION}

The major cause of degradation to the ecological condition of rivers is sedimentation, which not only leads to loss of valuable storage but a large amount of replacement cost as well. For impounding water or underground streams, dams are built which helps to retain water but at the same time, they are increasingly facing problems because of river sediment transport. It is estimated that about 50 cubic kilometers of sediment is trapped behind the world's dams every year, which not only causes the loss of capacity of reservoir but also causes aggradation in upstream, degradation in downstream, abrasion of structural components and clogging of narrow water passages with overall devastating effect in the environmental, technical and economic impact.

Sediment yield, which is the average sediment load passing through the particular section per year, is the most important factor to be determined during overall project planning and design of reservoir structures. Depending on the physical, technical, socio-economic and environmental conditions, different sediment management practices for reservoirs could be adopted. These techniques could be applied at different locations of the reservoir either at the upstream, within the reservoir, at the dam or at downstream with proper planning of sediment control measures. Hence, reservoir sedimentation is one of the major challenges in hydropower storage project (reservoir) and its proper management is indispensable for the sustainability of such projects.

\section{REFERENCES}

[1]. Proceedings of 9th International Symposium on River Sedimentation,2004,Yishang,China

[2]. Sultan Alam, Cecil Soileau and Ralph L. Laukhuff ., Sediment Transport Assessment in the Old River Control Area of the Lower Mississippi River Waterpower '93 Proceedings of the International Conference on Hydropower

[3]. Shailendra Basnyat ., Proceedings, Optimum use of Run-of-river hydropower schemes, Seminar in Trondheim,Norway, June 1999.

[4]. Gregory L. Morris, Jiahua Fan ., Reservoir Sedimentation HandJook, 1997

[5]. Gyanendra Prasad Kayastha ., Proceedings, optimum use of Run-of-river hydropower schemes, Seminar in Tronfdheim, Norway, June 1999.

[6]. Valérie Chabrier, Alain Comtet, Jacques Lovenq ., Evaluation of 50 year development on the Rhône valley, Rehabilitation of the old river at Pierre Bénite., ICOLD, Beijing Congress, 2000

[7]. Minoru Harada, Hiroshi Morimoto, Tetsuya Kokubo ., Operational results and effects of sediment bypass system. 1COLD Beijing Congres s, 2000

[8]. S. Alam ., Improving sedimentation management using multiple dams and reservoirs; The International Journal on Hydropower and Dams, volume nine, Issue 1,2002
[9]. V.K. Vanna., Virendra Johri ., P roceedings, Removal of silt through hydro-suction at Salal Dam, India.International Conference HYDRO 2003 Reservoirs (3/3)

[10]. Alessandro Palmieri - Farhed Shah-George W. Annandale. Ariel Dinar ., Reservoir Conservation The World Bank, Jillle 2003

[11]. Course Manual for M.Sc.level Student ,Prof. Dr.Durga P.Sangroula

[12]. A Paper Presentation on critical Evaluation of Sedimentation Management,S.Alam

[13]. A paper Presentation on Reservoir Sedimentation, George W.Annandale 